studies have cast doubt on cherished ideas by failing to reveal any significant association between haemoglobin levels in the general community and a variety of relevant symptoms, such as breathlessness and fatigue, even though a high proportion of people, especially women of child-bearing age, have haematological evidence of " anaemia." Furthermore, controlled trials of iron therapy have failed to show that it relieves the symptoms reported by such " anaemic" individuals." Clinical anaemia means, or should mean, an inadequate capacity of the blood to transport the oxygen needed by the tissues. The haemoglobin levels below which such inadequacy becomes clinically apparent are probably much lower than the levels conventionally used to define the incidence of " anaemia" in populations. There would seem to be a need for long-term, large-scale trials of the effect of adding iron to the diet.

\section{Changing Maternity Services}

For most women pregnancy and childbirth are normal and healthy processes. In Great Britain as in many other countries a considerable proportion of confinements were until recently conducted at home. But now more than threequarters of all births take place in an institution, and the proportion is rising annually. Nobody doubts that medically this change is desirable, for it is impossible to predict every case in which either the mother or her baby will need some special attention. And to move a mother from her home or from an inadequate institution to one where expert care can be given may increase the risk to the mother. Moreover, perinatal mortality is higher in these circumstances.

To meet present needs the council of the Royal College of Obstetricians and Gynaecologists reiterates in a recently issued report $^{1}$ the need for unification of all maternity services. This means that "the work should be in the hands of a team rather than an individual," and the council recommends that the general-practitioner obstetrician should be a member of the team. Thus the pattern advocated would be a team headed by the consultant and containing one or more generalpractitioner obstetricians. The report foresees the gradual disappearance of general-practitioner nursing-homes designated for normal cases, but concedes that it must be several years before district general hospitals, each with its maternity unit, and an integrated maternity service can come into being.

In its emphasis on teams headed by consultants working in fully equipped hospital units where virtually all babies would be born this report is expounding trends that already exist. The demand for delivery in hospital has increased so dramatically that the original Cranbrook ${ }^{2}$ estimate of $70 \%$ as an adequate figure for institutional confinements has already been exceeded. The $66 \%$ incidence in England and Wales in 1962 rose to $77 \%$ in 1967, and the figure for Scotland was $88 \%$. The annual increase now exceeds $2 \%$. These changes are made possible by the growing trend for early discharge to the care of domiciliary midwives after delivery in hospital. Meanwhile the number of domiciliary midwives decreased by $3 \%$ during 1963-7, and the number of home confinements fell by $32 \%$. In some areas the domiciliary service has virtually ceased to perform the work for which it was created and would not continue were it not for the demands of the increasing number of early-discharge patients.
According to the recent report on obstetrics in general practice $^{3}$ published by the council of the Royal College of General Practitioners three-quarters of all general practitioners are on the obstetric list. But it is clear that if the trends described and advocated in the R.C.O.G.'s report continue many of these general practitioners will cease to play a part in the obstetric services. Meanwhile there is no doubt about the popularity of the College's diploma in obstetrics among doctors in or destined for general practice, or that the many doctors who have received postgraduate training in obstetrics wish to practise it. The general practitioners' report is no doubt right in emphasizing (in italics) that "The relationship between the general-practitioner obstetrician and the consultant is one of the major problems of this service." It believes many of the difficulties may be attributed to a lack of discussion of policy at top level between representatives of the two groups, and epitomizes one aspect of the differences between them in these words: "Many consultants are only prepared to work in a service with general-practitioner obstetricians if they can lay down and apply strict rules of practice. Many general practitioners would only be prepared to work in a unified service if they could enjoy unfettered clinical responsibility." This argument has not been resolved, but the presidents of the two royal colleges responsible for these reports have announced that their councils have agreed on a joint committee to discuss the reports and their implications.

The emphasis on team work and integration is an important and welcome point of agreement in the views expressed by both royal colleges. They also both emphasize the need for practitioners engaged in obstetrics to be "vocationally trained" before admission to the obstetric list. Conversely, as more practitioners receive this training it is only reasonable that more opportunities should be created for them to practise obstetrics. In an integrated service with fewer home confinements this can be achieved only if more beds are made available in hospitals. Both colleges are agreed that these beds should be in general-practitioner units within the specialist maternity hospitals wherever this is possible. Of topical interest therefore is a scheme described by Professor Philip Rhodes at page 509 of the B.M.F. this week.

The College of General Practitioners' report states that if the isolated unit has any place it is in areas of scattered rural populations. When the ideal cannot be achieved, delivery in an efficient practitioner unit linked functionally with a consultant service is usually preferable to home confinement. This modification of earlier views on the siting of generalpractitioner units as expressed by the Nuffield Provincial Hospitals Trust, ${ }^{4}$ J. A. Stallworthy, ${ }^{5}$ and others is justified by the findings of the Perinatal Mortality Survey ${ }^{6}$ and the contributions of E. D. Acheson and his colleagues ${ }^{7}$ on record linkage.

When patients require transfer in an emergency late in pregnancy, or in labour, to consultant care, the perinatal

1 Council on Hospital Obstetrics and the General Practitioner, Hospital Obstetrics and the General Practitioner. Royal College of Obstetrobstetrics and the General Practitioner. London.

${ }^{2}$ Ministry of Health, Report of the Maternity Services Committee. 1959. H.M.S.O. London.

3 Obstetric Working Party, Obstetrics in General Practice. Reports from General Practice, 9. 1968.

- A Comprehensive Maternity Service. 1946. Nuffield Provincial Hospitals Trust. London.

6. Stallworthy, J., Brit. med. f., 1964, 2, 169. utler, N. R., and Bont

Hobbs, M. S. T., and Acheson, E. D., Oxford Record Linkage Study. Report No. 5: "A Study of Perinatal Mortality in the Oxford Area in 1962." 1965 
mortality is greatly increased. ${ }^{67}$ In one series the perinatal mortality rate for delivery at home and in general-practitioner units was 9 per 1,000 , but the rate for those transferred was 82 per 1,000 . These challenging contrasts occurred in a region (Oxford) which at the time had the lowest maternal mortality in England and Wales, was expanding its generalpractitioner units, and had implemented the concepi of area departments in which every practitioner unit was integrated, functionally though not always geographically, with a consultant unit. When emergency help is needed, distance means time, and time can mean death. These are the reasons why both royal colleges agree that physical and clinical integration of specialist and general-practitioner beds is the ideal, and team work is essential. To facilitate these developments it becomes increasingly urgent for representatives of both consultants and general practitioners to get together and agree on mutually acceptable plans. The extent of the agreement which already exists, as shown by the reports from the two colleges, augurs well for the meeting.

\section{Unintentioned Impact}

Last week the British Broadcasting Corporation screened a programme by its Horizon team called " Doctor's Dilemma." It dealt with the toxic side-effects of drugs, and was on B.B.C.2 at 8 p.m., a peak viewing time. Horizon, according to the Radio Times, was setting out to answer these questions: How are we trying to avoid another thalidomide tragedy? Are we technically equipped to assess (and avoid) the possible harm of the contraceptive pill ? Are we using antibiotics indiscriminately so that in the future we may regress to the pre-antibiotic era? All these are questions which deserve examination, and to which the public has an undoubted right to an honest answer. What is far less certain is whether such an inquiry can be done satisfactorily on a mass medium like television.

The intentions of the programme were exemplary. "For half a century," said the narrator, speaking of the therapeutic revolution, "it has been a success story." The audience saw quick takes of diseases such as leprosy and yaws before and after treatment. But then came the first shock: a woman who had been cured of her intestinal tuberculosis by streptomycin but left atoxic. Although only 55, she was in an old people's home. She was seen staggering along a pavement, and, interviewed, said that she could not work, became sick when she travelled, and was no longer an independent person. Visually the impact of this one case erased most of what had preceded it. The lesson that drugs can be extremely harmful was rammed home by a sequence showing thalidomide children. The stage set, the programme then got into its stride. The screen showed the toxicity-testing of drugs in pharmaceutical laboratories, and viewers were treated in turn to the tranquillizing of fighting fishes, the slicing of a frozen rat for autoradiographic tracing of a drug's metabolic progress, the extraction of rat foetuses for examination to exclude deformity, and, of all things, rabbits in wooden pillories having their rectal temperatures taken. No wonder one approving journalist wrote the next day that he had watched the programme " by turns nauseated and fascinated." It was fair comment.
It had to be admitted, however, that animals are the weak link in the chain of testing, "since no animal will respond to a drug in the same way as man." So from animals the programme moved to humans-volunteers on the contraceptive pill, in whom, viewers learnt, a diabetic type of glucosetolerance curve had developed. Next a clinical pharmacologist warned what may happen if drugs interact with each other in the body, or with foodstuffs-a point forcefully made on the screen by a controlled experiment with two rats, the one injected with food substance as well as antidepressant reacting as if to a prolonged electric shock. It was left to a psychiatrist who believes firmly in the value of antidepressants to try to redress the balance and justify the risks of using them. He said his piece and his patient gave a glowing testimonial, but by then only the more judicial of their audience would have been accessible. The remainder of the 40-minute programme concerned less disturbing questions. The transfer of bacterial resistance to antibiotics and the role in this of adding these drugs to animal feeds were well presented. The programme ended by glancing at how information about drugs reaches doctors and at some of the ways they can be helped to evaluate it.

Television programmes on medicine impose a responsibility on their producers which goes well beyond providing good television. Equally doctors taking part in them must realize how easily cutting or rearrangement can distort what they hope to convey, and their appearance may be taken as tacit assent. The audience is vast, and truly described as captive. It includes the sick as well as the healthy, the simple as well as the sophisticated. The side-effects of drugs, especially when directly linked to the emotive thalidomide tragedy, make an explosive mixture. The illustrations of their ill-effects on the Horizon programme were far more dramatic than those of their benefits. No doctor would wish to transfer even a part of his daily dilemma to his patients, but this is what this programme did.

\section{Allergy to Influenza Vaccine}

To meet the outbreak of Hong Kong A2 influenza expected this winter $^{1}$ many persons will seek immunization against it. During the last few years it has been shown that influenza vaccine gives immunity for at least six months to about $75 \%$ of people vaccinated, and many regard this as worthwhile protection, particularly for patients in whom the disease may lead to more serious sequelae. Though the Hong Kong virus is an A2 strain, it is sufficiently removed antigenically from those infecting our community in recent years for few people to have any natural immunity to it. The epidemic in the Far East occurred too late for the strain to be included in the vaccine produced earlier for use this winter. Accordingly, two vaccines will be available-the one containing representative strains of recent $A 2$ and $B$ influenza viruses and the other a monovalent vaccine containing only the A2 Hong Kong strain or an isolate of similar antigenic character.

A question to be considered is whether influenza vaccine carries a risk of sensitization to egg proteins contained in it. $^{2}$ The virus is grown by infecting the allantoic cavity of embryonated hens' eggs and, after incubation for two days,

1 Brit. med. f., 1968, 3, 757.

2 Davies, N. N.. Brit. med. F., 1968, 4, 327. 